\title{
Open sternum, cooler heart: The effect of surgical approach on myocardial temperature
}

\author{
Arbaz A. Momin, BS, ${ }^{a}$ Raphaelle A. Chemtob, MD, ${ }^{b}$ Diana C. Lopez, BS, ${ }^{a}$ A. Marc Gillinov, MD, \\ Per Wierup, MD, PhD, and Stephanie L. Mick, $\mathrm{MD}^{\mathrm{c}}$
}

\footnotetext{
From the ${ }^{\mathrm{a} C l e v e l a n d}$ Clinic Lerner College of Medicine of Case Western Reserve University, Cleveland, Ohio ${ }^{\mathrm{b}}$ Department of Thoracic and Cardiovascular Surgery, Heart and Vascular Institute, Cleveland Clinic, Cleveland, Ohio; and ${ }^{\mathrm{c}}$ New York Presbyterian Weill Cornell Medical Center, New York, NY.

Disclosures: Dr Wierup is a consultant for CryoLife, Edwards Lifesciences, and Medtronic. Dr Gillinov is a consultant for Edwards, Medtronic, Abbott, Cryolife, Johnson and Johnson, AtriCure, and ClearFlow. All other authors have nothing to disclose with regard to commercial support.

Received for publication Oct 31, 2019; revisions received Oct 31, 2019; accepted for publication Jan 3, 2020; available ahead of print Feb 6, 2020.

Address for reprints: Arbaz A. Momin, BS, Educational Institute, Cleveland Clinic Lerner College of Medicine of Case Western Reserve University, 9980 Carnegie Ave, Cleveland, OH 44195 (E-mail: momina@ccf.org).

JTCVS Techniques 2020;1:41-2

2666-2507

Copyright (C) 2020 The Authors. Published by Elsevier Inc. on behalf of The American Association for Thoracic Surgery. This is an open access article under the CC BY-NC-ND license (http://creativecommons.org/licenses/bync-nd/4.0/).

https://doi.org/10.1016/j.xjtc.2020.01.013
}

We previously demonstrated del Nido solution to be a safe alternative to conventional cardioplegia in adult isolated valve surgery; however, there is little information concerning factors that might influence its effectiveness. ${ }^{1}$ Because the heart is directly exposed to a number of factors influencing temperature (eg, operative lights, ambient operating room temperature of $19^{\circ} \mathrm{C}$ ) in a sternotomy and a robotic procedure, the heart remains predominately enclosed in the body cavity (with, perhaps, a lesser potential for radiant heat loss), we hypothesized that myocardial temperature may differ during mitral surgery performed through these approaches.

\section{MATERIALS AND METHODS}

We prospectively studied 50 patients who underwent isolated mitral valve repair with single antegrade dose $(20 \mathrm{~mL} / \mathrm{kg})$ del Nido cardioplegia as part of a quality improvement study. A total of 25 patients underwent a median sternotomy, and 25 patients underwent robotic repair. Because of the limited exposure in robotic cases, the only cardiac structure equally accessible for measurements in both approaches was the body of the right atrium (RA). RA temperatures were collected at 7 different time points during the surgery: the start of cardiopulmonary bypass; the start of cardioplegia infusion; the conclusion of cardioplegia administration; 10, 20, and 30 minutes after aortic crossclamp; and immediately after aortic crossclamp removal. All patients were systemically cooled to $32^{\circ} \mathrm{C}$ with cooling started after crossclamp. Room temperature $\mathrm{CO}_{2}$ was used to flood the field in both approaches. Temperatures were collected using a noncontact infrared thermometer (Fluke 62 Max, Fluke Corp, Everett, WA) calibrated according to the manufacturer's guidelines). Topical cooling was not used in either approach. We compared temperatures between groups at these time points. Linear mixed model was fit containing main effects for surgical type, time, and a surgical type by time cross-product term using SAS statistical software (SAS version 9.2; SAS Institute, Inc, Cary, NC). Model contrast statements were used to test for differences among the surgical types for each time point.

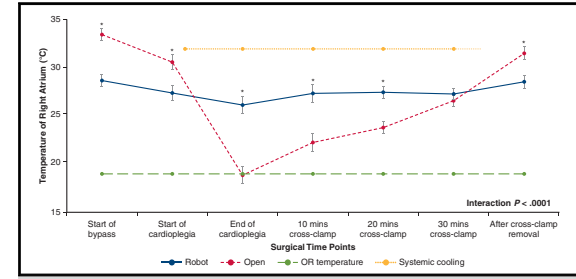

RA temperatures during robotic and median sternotomy (open) operation.

CENTRAL MESSAGE

The potential for decreased

myocardial cooling in robotic

mitral valve repair should be

taken into consideration.

See Commentaries on pages 43,44 , and 46 .

\section{RESULTS}

Patient characteristics and crossclamp times are shown in Table 1. Crossclamp times in robotic cases were significantly longer compared with sternotomy cases. Temperatures were higher in $\mathrm{RCs}$ at the end of cardioplegia administration $\left(26.2^{\circ} \mathrm{C}\right.$ vs $\left.18.8^{\circ} \mathrm{C}, P<.0001\right)$ and at $10 \mathrm{mi}-$ nutes $\left(27.4^{\circ} \mathrm{C}\right.$ vs $\left.22.2^{\circ} \mathrm{C}, P=.0001\right)$ and 20 minutes $\left(27.5^{\circ} \mathrm{C}\right.$ vs $\left.23.8^{\circ} \mathrm{C}, P<.0001\right)$ after crossclamp, but equalized at 30 minutes (Figure 1).

\section{DISCUSSION}

To our knowledge, this study is the first to directly assess approach-related cardiac temperature differences in patients

TABLE 1. Patient characteristics

\begin{tabular}{lccc}
\hline & Robot $(\mathbf{n}=\mathbf{2 5})$ & $\begin{array}{c}\text { Median } \\
\text { sternotomy }(\mathbf{n}=\mathbf{2 5})\end{array}$ & $\begin{array}{c}\boldsymbol{P} \\
\text { values }\end{array}$ \\
\hline Age, y & $60.8( \pm 15.2)$ & $55.74( \pm 8.77)$ & .171 \\
Male gender & $19(79.2)$ & $16(66.7)$ & .329 \\
BMI & $26.12( \pm 2.75)$ & $26.17( \pm 3.86)$ & .962 \\
$\begin{array}{c}\text { Body surface } \\
\text { area }\left(\mathrm{m}^{2}\right)\end{array}$ & $1.99(1.78-2.21)$ & $1.98(1.82-2.14)$ & .519 \\
$\begin{array}{c}\text { Crossclamp } \\
\text { time (min) }\end{array}$ & $64.0(55.75-68.75)$ & $45.5(35.0-49.4)$ & $<.0001$ \\
\hline
\end{tabular}

Data are presented as mean ( \pm standard deviation), median (interquartile range), or number (\%). BMI, Body mass index. 


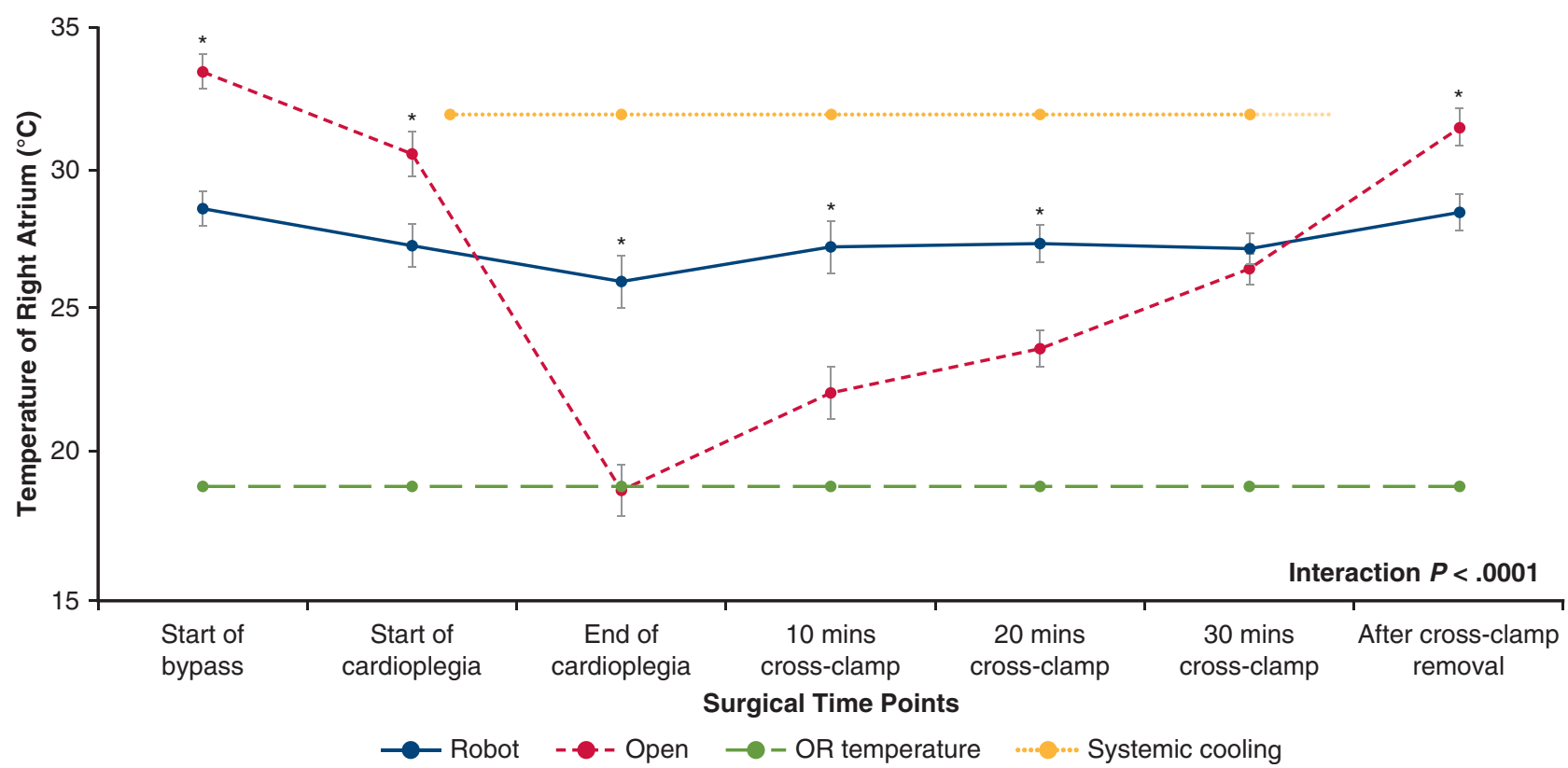

FIGURE 1. Temperatures of the RA at 7 different surgical time points in patients undergoing mitral valve repair by a robotic or median sternotomy (open) approach with del Nido cardioplegia. Asterisks indicate statistical significance $(P<.05)$. Patients were systemically cooled to $32^{\circ} \mathrm{C}$ after crossclamp application. $O R$, Operating room.

undergoing mitral repair using del Nido solution. We found that RA temperatures decreased precipitously once singledose cooled $\left(4^{\circ} \mathrm{C}\right)$ del Nido solution was administered antegrade in sternotomy cases and remained in a hypothermic state until 30 minutes after crossclamp in these cases. In contrast, RA temperature in robotic cases tended to remain at a stable, warmer temperature throughout the surgery. These differences may be due to smaller potential for cardiac heat dissipation in more enclosed spaces, differences in venous drainage, or radiated heat from robotic camera tip. ${ }^{2}$ Given that crossclamp times in robotic cases were significantly longer than in sternotomy cases, it would seem that the metabolic activity of the myocardium may be less suppressed by cooling for a longer period of time in robotic cases and thereby retaining more metabolic activity overall than the myocardium in open cases. This finding underscores the need for meticulous care to other factors influencing cardioprotection in 1-shot cardioplegia; these include attention to adequate delivery and excellent venous return to limit myocardial rewarming. ${ }^{1}$ Additionally, it may suggest that a greater degree of systemic cooling in robotic cases should be considered. Further studies are required to determine whether there is a significant difference in clinical complications associated with increased myocardial temperatures in robotic cases versus sternotomy cases.

\section{Study Limitations}

This study was conducted at a single institution, limiting its generalizability. Because of the limited exposure in robotic cases, the only cardiac structure that was equally accessible for measurements in both approaches was the RA. The noncontact nature of the temperature probe increases the probability of ambient temperature artifact from surrounding tissues. We cannot comment on the temperature of the ventricles in this study, and the work represents only the beginning of the consideration of this topic. Because of the relative paucity of sternotomy cases at our institution, patients were not matched or randomized to either approach, increasing the probability of unadjusted confounders. The study was not powered to detect a difference in markers of myocardial protection.

\section{CONCLUSIONS}

In patients undergoing isolated mitral valve repair with 1-shot del Nido cardioplegia, the myocardium may remain warmer for a longer period of time in robotic procedures than in the conventional approach. This finding should be a consideration in the procedural planning and conduct of robotic cardiac surgery.

\section{References}

1. Mick SL, Robich MP, Houghtaling PL, Gillinov AM, Soltesz EG, Johnston DR, et al. del Nido versus Buckberg cardioplegia in adult isolated valve surgery. J Thorac Cardiovasc Surg. 2015;149:626-36.

2. Moss E, Halkos ME, Binongo JN, Murphy DA. Prevention of unilateral pulmonary edema complicating robotic mitral valve operations. Ann Thorac Surg. 2017;103: 98-104. 